\title{
Nada Menos que Apenas Nomes: os etnônimos seriais no sudoeste amazônico
}

\author{
Oscar Calavia Sáez \\ Universidade Federal de Santa Catarina, Florianópolis, Brasil \\ E-mail:occs@uol.com.br
}




\section{Resumo}

A proliferação de etnônimos que não correspondem a unidades ou fronteiras sociais identificáveis tem sido uma caraterística da etnografia do sudoeste amazônico. Lá, a junção de um sufixo significando "povo" como virtualmente qualquer nome (especialmente de animais, mas também de plantas, acidentes geográficos ou qualidades morais) produz infindáveis listas de denominações étnicas nas diferentes línguas locais. Esse traço tem sido tratado dentro de um quadro realista/nominalista: tais nomes seriais poderiam ser um simples "ruído" etnográfico: informações e interpretações deturpadas que deveriam ser substituídas por nomes reais numa proporção biunívoca de um nome para cada povo. Postula-se que mesmo se não denotam unidades sociais reais e extensivas, os nomes seriais são, contudo, reais e desempenham tarefas também reais, eles conotam descrições múltiplas da rede social, dando passo a episódios de fissão e de fusão.

Palavras-chave: Etnônimos. Sudoeste Amazônico. Yaminawa. Perspectivismo. Pano.

\section{Abstract}

The proliferation of ethnonyms without a clear correspondence to identifiable social units or boundaries has been a salient feature in the ethnography of Southwestern Amazon. There, the addition of a suffix meaning "people" to virtually every name (specially animals, but also plants, geographical accidents or moral qualities) produces endless rows of ethnic denominations in the different local languages. This feature has been addressed within a realist/ nominalist frame: such serial names would be plain ethnographical noise: misinformation, misconstruction -therefore, they should be substituted by real names in an bi-univocal group to name basis. I argue that even if they doesn't denote real, extensive social units, serial names are nonetheless real, performing real tasks: they connote multiple renditions of the social network, opening the way to fission/fusion episodes.

Keywords: Ethnonyms. Southwestern Amazon. Yaminawa. Perspectivism. Panoan. 


\section{Introdução}

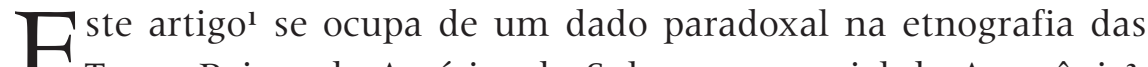
$\beth$ Terras Baixas da América do Sul, e em especial da Amazônia². Trata-se desses conjuntos de termos, às vezes muito numerosos, que supostamente designam partes de um grupo. Em geral estão formados pela junção de uma série de nomes de animais, plantas ou outras qualidades a um sufixo que denota "gente" ou "povo" - embora essa denotação, útil para uma tradução de urgência, eluda, normalmente, densas conotações. Conjuntos como o x-nawa dos Pano, o x-madiha dos Kulina, o x-masá dos Tukano, o oró-x dos Wari, o x-djapá dos Kanamari, os diversos -iana ou -koto dos Karib, e um etc. provavelmente longo. Fala-se deles, de praxe, como "subgrupos" ou como "grupos de denominação"; aqui se usará, de preferência, a definição mais genérica (e, espera-se mostrar, menos inadequada já que não totalmente adequada) de "etnônimos".

\section{Ruído}

O paradoxo a que se refere consiste em que os etnônimos se manifestam, ou geralmente alcançam um destaque considerável nas etnografias, apesar de seu rendimento interpretativo muito reduzido, praticamente nulo. Listas às vezes muito numerosas desses "subgrupos" são pacientemente anotadas e expostas, sem que, no entanto, seja possível atribuir-lhes uma extensão e muito menos funções específicas. Poucas vezes se insinuam quais seriam as fronteiras desses "subgrupos", ou se dão critérios inequívocos de pertença a eles: eventualmente, os próprios nativos não conseguem definir a qual desses subgrupos 
pertenceria este ou aquele sujeito particular. Para não falar das suas funções: descendência, definição da aliança, algum tipo de classificação totémica, de distribuição ritual? É preciso muita liberdade com os dados para outorgar algum uso inequívoco a essa taxonomia que mais parece apontar para um excesso gratuito de atividade classificatória, mais uma dessas "partes malditas" da sociologia ameríndia.

Listas numerosas de etnônimos acompanham há muito tempo os relatórios etnográficos. Suas dimensões podem ser apreciadas nos artigos do Handbook of South American Indians (Steward, 1948), que chegam a enumerar uma centena de supostos grupos Pano, ou na etnografia de Frikel (apud Fajardo Grupioni, 2011, p. 125) que chega a citar 144 "tribos" no norte do Pará, ou no livro de Alves da Silva (1977) que, entre suas páginas 75 e 103, enumera nada menos que 332 "divisões" dos grupos do Uaupés. Durante muito tempo, e estendendo a eles modelos familiares ao pesquisador, agiu-se como se eles fossem unidades efetivas, espraiadas por uma hierarquia mereológica: seriam partes de partes, ou conjuntos de conjuntos. Cá e lá se despendeu um esforço considerável - despende-se ainda - em discussões sobre a correta identificação de um povo, ou sobre a filiação histórica de um etnônimo atual a outro do passado, ou sobre a adequada hierarquização dos nomes.

O paradigma que fundamentava esses esforços foi descartado há muito tempo. Refere-se aqui a esse modelo "africano" ou a rigor "africanista" (Seeger et alii, 1979, p. 8-9) que procuraria unidades discretas equivalentes a clãs, linhagens e sublinhagens. Numa versão menos renhida com a experiência de campo, os nomes que nos ocupam foram sendo depois imaginados como próprios de parentelas corresidentes do tipo que Peter Rivière (1984) descreveu para as Guianas, ainda partes de um agregado frouxo, mas sem essas hierarquias lógicas de pertença que antes se buscavam sem nenhum fruto. Muitas vezes entendidos como uma memória de unidades desaparecidas, "tribos extintas" cujo número superava o das tribos sobreviventes, que vez por outra ressurgiam em algum lugar, à medida que a investigação etnológica prosseguia ${ }^{3}$. Esse tratamento tem vantagens evidentes sobre o anterior, a principal sendo a que mantém um vínculo muito mais direto 
com o próprio testemunho dos nativos, ou, ao menos, com uma parte importante desse testemunho. É o que acontece, por exemplo, com o panorama descrito por Vilaça (2004): os grupos Oro-x que compõem o conjunto Wari referem-se a parentelas idealmente endógamas que outrora tinham uma vida independente antes que as circunstâncias do contato com a sociedade nacional as empurrasse a se reunir e a se misturar em assentamentos maiores, em torno de missões ou postos da FUNAI. É a História, uma história movida desde o exterior, quem tem promovido a mistura, esvaziando o poder definidor dos subgrupos, rompendo a sua endogamia ideal, etc. Mas, como a própria Vilaça anota - e como o fazem outros autores que seguem a mesma linha de raciocínio - há muito que duvidar do próprio modelo de Rivière e desses testemunhos sobre o passado, porque abundam os dados - e com isso refere-se aqui a outros testemunhos dos mesmos nativos que põem em dúvida, mesmo para o passado, esse caráter discreto dos subgrupos. Ou, mais interessante ainda, que o confirmam, mas projetando-o sobre um plano utópico: por exemplo, nas visões do toé (Gow, 1987, p. 283), ou na cartografia do céu (Calavia Sáez, 2006, p. $223,348)$ em que a mistura é eludida e se vive autêntica e incestuosamente "entre si".

Ou seja: há, sim, conjuntos endogâmicos bem diferenciados, designados por esses nomes inumeráveis. Mas eles não têm curso no plano terrestre e cotidiano, em que impera a mistura e a confusão, senão nessa outra realidade que pode se conhecer depois da morte, ou mediante o uso de uma droga visionária. Esse passado em que os subgrupos eram reais é vizinho dessa outra dimensão atual, porém apenas acessível aos xamãs ou aos mortos. Deixando de lado aquela procura de taxonomias produtivas que nunca obteve qualquer resultado concreto, essa outra interpretação tem pelo menos o mérito de levar o estudo dos subgrupos a outro terreno, o das ideologias indígenas da socialidade.

O realismo ingênuo com que outrora se procuraram referentes para tantos nomes tem levado, por reação, ao seu descrédito. Os conjuntos de etnônimos, que alguma vez aspiraram a constituir uma informação muito valiosa, passaram há muito tempo a ser considera- 
dos como um "ruído", capaz de dar alguma pista sobre questões secundárias, mas nocivo para uma investigação ordenada das essenciais.

Ruído que, de resto, tingia-se de colorações morais negativas, porquanto ele era gerado, ou pelo menos amplificado, pelos processos coloniais e por estratégias duvidosas de pesquisa. Assim, por exemplo, boa parte desses etnônimos são termos derrogatórios, às vezes marcadamente derrogatórios: "povo bosta", "povo vampiro", "povo de ladrões". Isso nada tem de excepcional no universo dos etnônimos em qualquer rumo do planeta, mas os agentes coloniais têm mostrado certo prazer em etiquetar os povos com os insultos que uns dedicavam aos outros, e não podia ser de outro modo na medida em que a colonização sempre avançou pelas frestas que lhe fornecia a hostilidade entre os colonizados. Os etnógrafos somaram-se acriticamente a esse hábito, favorecido também pelas suas fraquezas de método: uso corriqueiro de traduções improvisadas, atenção escassa à transcrição detalhada dos nomes ou ao seu contexto. Isso multiplicava, serializava e fazia mais insidiosa essa etnomaledicência: assim, Sharanahua (povo bom) podia tornar-se Saranahua (povo de um determinado tipo de abelha, ou, em definitiva, "abelhudo"). Mais do que ruído, a proliferação de nomes era, assim, o rumor da malignidade local, que os cientistas consagravam com solenidade. No melhor dos casos, ou seja, quando o nome carecesse de conotações muito negativas e fosse aceito pelos interessados, tratava-se, todavia, de etnônimos "dados por outros" e, assim, essencialmente falsos.

\section{Autodesignação, Cosmografia, Topologia}

O que tem se imposto sobre esse "ruído" é uma tríade de sistemas de denominação reconhecidos (em diferentes graus) como reais, ou pelo menos mais reais.

O primeiro deles é o da grade étnica oficial, essa que pode se encontrar nos mapas, nos relatórios etnográficos ou nos documentos dos órgãos indigenistas: que será mencionada no final deste artigo. O segundo é o da autodesignação. O terceiro é algo que, por economia conceitual, será chamado de heterodesignação; poderia ser chamado também de sistema cosmográfico. 
A autodesignação tem alcançado sua máxima visibilidade com a decisão etnográfica, predominante nos últimos decênios, de dar com os nomes verdadeiros, que são, como se entende, aqueles que um povo usaria para falar de si mesmo. A multiplicação dos etnônimos teve seu ápice numa época de etnógrafos de passagem, que em extensos e rápidos percursos por uma região multiplicavam os povos nominados pelo número dos povos nominadores. Etnografias mais sólidas, baseadas em períodos de campo prolongados e num domínio maior, ou pelo menos de primeira mão, da língua indígena, têm outorgado à autodesignação a função de "nome verdadeiro", e a tem proposto como tal aos órgãos do estado, fazendo das autodesignações nomes oficiais dos grupos. O nome é verdadeiro não apenas porque resulte de uma indagação direta sobre "como é que vocês se chamam a si mesmos", como também porque a resposta costuma incluir um adjetivo desse tipo: "homens de verdade", "humanos legítimos"4. A etnologia Pano forneceu bons exemplos desse recurso, sendo o mais conhecido de todos eles o "Huni Kuin", "gente verdadeira", a autodesignação que no último trecho do século XX passou a substituir quase por completo o nome "Kaxinawá" (gente-morcego). Antes de se tornar um nome oficial, Huni Kuin denotava - continua denotando, no vernáculo - uma posição dentro de um campo semântico da identidade que inclui dois princípios antitéticos e duas posições intermediárias: um "nós", um "semelhante a nós", um "diferente de nós" e um "outro" absoluto (Deshayes; Keifenheim, 1982; Keifenheim, 1992). Huni Kuin corresponde à primeira posição. Um pouco mais simples, o modelo Yaminawa (Townsley, 1988) distingue um yura ("corpo", referido a esse lugar social desde o qual fala o nativo) um yura utsa que designa elementos próximos e equivalentes, porém separados desse "nós" inicial, e, finalmente um nawa aplicado a uma amplíssima variedade de "outros" que incluem o inimigo, o homem branco, talvez a onça e os seres poderosos e perigosos em geral. Esse quadrângulo e essa tríade têm inúmeros equivalentes em outras línguas ameríndias, e a clave de sua organização está nessa síntese de dualismo concêntrico (Viveiros de Castro, 1993; 1995) que na maior parte dos sistemas de parentesco amazônicos combina as dicotomias com um gradiente de proximidade. 
Não é mais novidade - mas pode ser útil insistir no ponto - dizer que consagrar a autodesignação como nome verdadeiro - independentemente do fato de que muitos povos a tenham abraçado com entusiasmo, e com todo direito - é um fruto do processo de colonização e dos equívocos de tradução, em medida não menor que o velho positivismo dos clãs, os subgrupos e as províncias. Não que esses termos do tipo "gente verdadeira" sejam alheios à língua ou à experiência dos povos em questão, nem que se trate de uma má tradução. Mas é demasiado supor - demasiado, ao menos, até que os nativos o põem em prática que termos desse tipo possam ser tidos como autodesignações. Apenas a soma de uma visão individualista com uma metafísica introspectiva pode concluir que a identidade seja algo que o sujeito extrai de si mesmo. Por motivos pragmáticos - e a não ser em exercícios reflexivos na frente de um espelho real ou imaginário, que não são comuns em toda e qualquer parte - os sujeitos não "se chamam a si mesmos", e quando o fazem usam, em geral, um nome dado por outros. A atribuição de nomes inventados pelos vizinhos ou pelos colonizadores não constitui, como muitos etnógrafos parecem sugerir, recurso discriminatório impingido aos povos do quarto mundo: foi, de fato, a norma por toda a parte até a chegada de um estado que defina os seus limites e o seu nome. E, mesmo então, a postulação de uma "totalidade" e a sua nominação pelo estado continua a ser um privilégio de outro - esse outro superlativo que é o próprio Estado: uma arqueologia dos nomes adotados pelos estados-nação europeus revelaria um campo tão cheio de equívocos, extrapolações e maledicências quanto o da etnonímia amazônica. E não pode estranhar que, desde que a autodeterminação dos povos autóctones tem ingressado na agenda política global, a "autodenominação" tenha sido imaginada como um requisito necessário para esses autóctones; ela condiz com todo esse panorama autárquico e eventualmente solipsista que se entende como próprio (um atributo ou uma carência) dos povos sem estado.

Mas essas autodenominações auferidas no campo não são, em origem, nomes. Pensemos num caso paradigmático, relatado por Zarzar (1987). No início dos anos de 1980 do passado século, um grupo isolado de falantes de língua Pano foi contatado no Parque Nacional del Manu, na Amazônia peruana. Os Yaminawa próximos, que colaboraram na 
operação e passaram em certa medida a patrocinar os novos vizinhos, passaram a chamá-los de Parquenahua, gente do Parque. Os indigenistas, pouco depois, optaram por evitar esse híbrido e o substituíram por Yura, a palavra com que eles respondiam às indagações sobre sua identidade. Yura, como antes vimos, é corpo, um termo usado também pelos vizinhos, que se consideram corpos também, embora se sintam diferentes dos Parquenahua. Os novos parceiros ficaram assim como Yura, o que foi um modo de dar-lhes como nome algo que não era a rigor um nome. As autodenominações são, em princípio, expressões pronominais, pronomes cosmológicos (Viveiros de Castro, 1996) que dão voz a uma primeira pessoa do plural. E os pronomes, por muito que a palavra aluda a uma substituição - estariam lá em nome do nome - não representam necessariamente um nome; os pronomes se manifestam de um modo diferente ao do nome. Pronomes exercem como sujeitos ao igual que os nomes, sem ser, como os nomes, facilmente objetiváveis. Sua extensão é enormemente elástica: essa primeira pessoa invocada por termos como huni kuin ou yura pode se referir a um núcleo muito restrito de parentes, abranger uma ou várias aldeias, incluir os aliados habituais, se ampliar até incluir todos os "índios" ou além para, é claro, contrair-se a seguir. O mesmo acontece com seu oposto, um termo como nawa, que por muito que aluda à alteridade absoluta e, portanto, a distância, pode surgir de repente dentro da própria unidade doméstica: casar com o inimigo é, sabe-se, muito comum. Transformar o pronome em nome propriamente dito é um mal-entendido, mesmo se um mal-entendido fértil: nominalmente, resgata a identidade de um povo das aderências da história colonial, o instala num novo começo com a pureza da origem, e esse atributo de "legítimo" incluído em termos como Huni Kuin ganha contornos de orgulhosa reivindicação cultural.

O terceiro sistema, que propus chamar de heterodesignação, seria em aparência um fenômeno de cunho oposto, carregado com todo o ônus da história: suas ficções, seus abusos, seus equívocos. Várias contribuições ao seminário em que este volume se originou focam esse tipo de designações. Andrello, no seu artigo, trata de um excelente exemplo: Baré, que de designar em alguns contextos uma população específica alça-se a um uso muito mais amplo, seja como 
um genérico para "índio" ou, mais exatamente, índio sujeito ao cativeiro dos "resgates"; ou, contrariamente, índio que virou branco, e agente desses mesmos "resgates". "Tukano" desempenha por sua vez o mesmo papel de Baré, mas numa escala geográfica menor, e aplicado a coletivos que podem ser "na verdade" yepa-masa ou x-masa. O mesmo pode se dizer do artigo de Deturche, com esses Cambeba e Cocama designando falantes de uma língua Katukina, os quais contam com um sistema de designação alternativo, - pönhiki, totalmente em desuso e raramente lembrado. Ou dos nomes atribuídos aos Hupda dos quais tratou a contribuição de Pedro Lolli.

Estamos no meio de um sistema de nominação povoado de estereótipos, termos genéricos e identificações incertas - e de todo o abuso factual que pode haver por trás deles. Mas há uma ordem nem tão oculta nesse conjunto de erros que, de resto, dificilmente teria esperado o regime colonial para surgir. Essa ordem põe em cena duas ou três ("duas ou três" não é uma conta imprecisa, mas essa combinação de dualismo e concentrismo antes citada) categorias de nomes genéricos. Um deles é o que se refere ao "selvagem", com dezenas de expressões locais: chunchos, aukas, jívaros, tapuias, e índios "bravos" em geral. Outro é o que alude aos índios "mansos", eufemismo reservado para os índios que estão se civilizando ou civilizando a outros, submetidos a cativeiro ou agentes desse cativeiro. Longas páginas da história dos povos indígenas têm se dedicado a esses nomes que, aliás, transitam de um polo a outro: "tapuia" ou "caboclo" têm variado, e variam, de designar o bárbaro a designar o índio em vias de virar branco. Em contextos mais reduzidos, esses genéricos célebres podem ser substituídos por outros nomes que constam também na grade oficial. Acabou-se de citar o caso de "Tukano"; "Yaminawa" foi também, durante muito tempo, apenas o nome reservado para o último grupo Pano a sair da floresta.

Por muito que venham à tona de modos muito diferentes, e, por muito que lhes demos valores morais muito diferentes, as auto e as heterodesignações operam de maneira semelhante. Trata-se, em ambos os casos, de termos perspectivos, ou de termos egocentrados, que a partir de um ponto de vista criam um espaço rebelde a limites absolutos. Esse "nós" ativado por termos como Yura ou como Huni Kuin tem 
uma extensão que varia amplamente, podendo incluir elementos que em outras ocasiões ficariam como yurautsa ou mesmo como "nawa". Do mesmo modo, a condição de "Baré", "Tukano", "Chuncho", "Auka" ou "Tapuia" é relativa à posição do enunciador, que via de regra localizará sempre os seus selvagens rio acima e os seus mansos rio abaixo (veja-se em Carneiro da Cunha (1998) essa inserção da perspectiva na paisagem e no sistema de aviamento da Amazônia), rumo a essas alteridades absolutas dos hiperselvagens e dos hipercivilizados ${ }^{5}$. A heterodesignação pode possuir também a mesma flexibilidade do pronome. Um mesmo jogo topológico se executa em ambos os casos: a distância faz supor a diferença, a estranheza implica a distância. A escolha dos termos inseridos nesse jogo é arbitrária: termos oriundos do vernáculo, de uma língua geral ou um léxico geral desempenhamse do mesmo modo ${ }^{6}$.

Mas, se nesse aspecto pronominal, as heterodesignações se aproximam das autodesignações, a diferença delas são ricas em informação histórica ou, como sugerido inicialmente, cosmográfica, que nem sempre tem sido convenientemente explorada. Elas carregam muito mais que uma posição relativa no sistema fluvial ou no sistema de aviamento. Elas falam (seleciona-se aqui alguns dados de Calavia Sáez (2006, p. 241-247 e 255-260) da persistente ideologia da selvageria, ou do reconhecimento de hibridações - esses Chontaquiro, esses Quíchua-Canelo - ou de rearranjos da distribuição, quando a pluralidade desaparece em favor de etnônimos mais gerais (o caso da série Shipibo-Conibo-Shetebo, no Ucayali), ou pelo contrário se atomiza em denominações muito diversas e irredutíveis. Fala do recurso a nomes genéricos, ou a nomes alheios dos que se espera uma melhor caraterização ou uma maior saliência no campo étnico - como esses Cambeba ou Cocama - ou de manobras de assimilação ou disfarce: é o caso dos Katukina-Pano, que em começos do século XX se fazem passar por Katukina esperando disso uma atitude mais benévola dos brancos que reconheciam os Katukina como índios mansos e receavam os Pano como índios selvagens. Em resumo, numa história na qual com frequência não se tem mais do que nomes, é inevitável que eles carreguem uma informação valiosa, por si mesma ou na falta de outra. 


\section{Nomes Intensivos}

Mas o tipo de nome que é objetivo central deste artigo - referese a esses clusters seriais de nomes do tipo nawa, madiha, djapá, massá, etc. - comporta-se de maneira muito diferente. São nomes propriamente ditos, e a alternativa auto/heterodesignação pouco significa no seu caso; são, em princípio, nomes dados por um "outro", mas à sua atomização acompanha a desse outro - é amiúde um vizinho ou um parente próximo quem pode enunciá-lo como verdadeira identidade de alguém.

São imunes a descrições extensivas ou topológicas: não há como dizer quem são todos esses nawa e também não há como ordená-los num gradiente do mais próximo ao mais distante. Esses etnônimos embaralham a designação dos grupos, mas em troca permitem descrições alternativas deles: entre os Yaminawa recolheu-se diferentes conjuntos de etnônimos que, respectivamente, descreviam um sistema de metades (os Yaminawa seriam um binômio de Xixinawa e Yawanawa, praticando uma troca matrimonial restrita), ou como um tetrágono que organizaria identidades com atributos animistas (um povo dos animais do mato, outro do fundo das águas, outro do alto das árvores, outro das queixadas), ou bem, enfim, como um agregado de "raízes" que se desdobram retrospectivamente, apontando aos atuais Yaminawa como o resultado da confluência de inúmeras linhas. Nessa versão, obtida dos eruditos da aldeia, o conjunto alcançava toda a sua potência: Bashonawa, Mastanawa. Kaxinawa, Chitonawa, Shaonawa, Sharanawa, e um etc. virtualmente interminável. Mas, essas descrições, como já foi dito no início, não são confirmadas por qualquer outra experiência nem se comunicam entre si. Os conjuntos etnonímicos aos quais se refere parecem brotar infinitamente de um único ponto, e não de uma morfologia social: se extensão houver, essa seria temporal, por aludir a identidades do passado ou de um futuro utópico.

Se, apesar de todos os inconvenientes descritos no início do artigo, a confusão etnonímica tem mantido sua atração sobre os pesquisadores, e continua se deixando ver nos textos, deve ter sido pela insistência dos nativos. Os nativos têm interesse em falar dela. 
Falam dela embora o pesquisador não pergunte, e falam dela quando o pesquisador espera que falem de outras coisas.

Essa insistência não deveria ser entendida como casual, como algo que não pode senão emergir, antes ou depois, numa interação continuada. O contexto da sua enunciação sugere, às vezes, algo muito mais intencional, uma resposta à interrogação do forasteiro, que quer saber com quem está falando, "quem são vocês, qual é o seu nome". Denise Fajardo, na sua intervenção no seminário que deu origem a este dossiê, descrevia o diálogo que, logo na sua primeira chegada ao campo, tinha determinado seu interesse pelos etnônimos: ao perguntar se naquelas casas residiam os Tiriyó, sem outro intuito que confirmar que tinha chegando ao lugar pretendido, um rapaz lhe ofertou, em lugar dessa confirmação, uma desnorteante profusão de nomes, que, a depender do ângulo e do gosto, poderiam designar melhor esses "Tiriyó". Guerreiro, neste volume, alude a algo muito parecido, dessa vez referindo-se ao nome das aldeias: "Os Kalapalo, com quem tenho trabalhado, podem deixar o interlocutor confuso quando dizem que uma de "suas" aldeias seria, "na verdade mesmo", Jagamü, enquanto outra seria Uagihütü, outra Lahatua [...]". A minha experiência foi a mesma. Os Yaminawa reconheciam ser os Yaminawa, por um bom motivo: "o branco nos deu esse nome", mas "na verdade" eram muitas outras coisas; esse "na verdade" nunca era uma conclusão, mas o anúncio de que por trás de qualquer identidade que se venha a estabelecer haverá sempre outra "mais real".

Os etnônimos aos quais se refere, é bom dizer, aparecem sempre depois. Ou seja, quase nunca se oferecendo como uma descrição canônica, antes como uma espécie de versão lateral ou oculta, remetendo a uma realidade que se intui mais efetiva.

Os etnônimos, é bom reconhecer, representam um dispositivo totémico, em toda a plenitude do que essa palavra pode significar depois da "transposição de nível" lévi-straussiana: ou seja, põem em correlação uma série "social" com uma série "natural". Não se deve dar a esse "totemismo", porém, um alcance excessivo. O valor classificatório desse paralelo é limitado e defectivo: é um sistema classificatório que raramente sai de sua aparente gratuidade. 
Quando o faz, a grade pode expressar qualidades psicológicas individuais, hipoteticamente fundadas na genealogia; crianças Piro malcomportadas mostram seu lado "yaminawa" (Gow, 1993); segundo me disse um dos meus interlocutores Yaminawa, a diversidade de nomes constitui um "horóscopo dos índios". Podem, também, ser mobilizados como emblemas políticos, inclusive na arena do multiculturalismo: o caráter gregário, unido, das queixadas, e a sua firmeza "tribal" eram invocados com orgulho pelos líderes Yawanawa ("povo queixada") no auge do seu renascimento cultural. Como mostra Fajardo (2011) na sua síntese a respeito dos etnônimos esses organizam diferenças, mas sem elaborar com elas um sistema fechado e completo, mantendo-se pelo contrário como uma obra em perpétuo andamento.

Os etnônimos podem remeter também, remetem, aliás, com frequência, à mitologia. A uma mitologia muito focada em episódios de transformação e numa percepção animista do universo. A multidão dos etnônimos se superpõe a uma cosmologia perspectivista. Ou seja: os relatos míticos descrevem com frequência um universo em que queixadas, onças, sucuris, juritis, macacos e mesmo outros elementos menos habituais como protagonistas (árvores da floresta ou barrancos do rio, por exemplo) se mostram como "povos", ou como "humanos". Mas o fazem numa situação em que seria possível - acontece às vezes, de fato - lidar com povos indiscutivelmente humanos que respondem aos mesmos nomes de povo-queixada, povo-onça, povo-sucuri etc., aos quais, de resto, é possível atribuir, sempre que pareça conveniente, as caraterísticas próprias de cada uma dessas espécies. Isso torna impossível definir se o relato está a tratar de humanos com nome animal ou de animais com caraterísticas humanas. A diferença entre uma recepção segundo o "perspectivismo ameríndio" (Viveiros de Castro, 1996; Lima, 1996) e segundo um, diga-se, pensamento naturalista, é que para o segundo essa ambiguidade é de fato ambiguidade, um jogo de palavras que talvez precisaria ser esclarecido (estamos a falar de humanos ou de animais?); para o primeiro obviamente não. Ou seja, fora desses raros momentos em que a analogia totémica é ativada ("os yawanawa são como as queixadas"), o que se tem é uma descrição em que coletivos animais e humanos compõem uma única série social. É desconhecida 
até que ponto essa série única aparece em outras regiões etnográficas, mas no caso do sudoeste amazônico o faz com regularidade, como o manifestam, ao lado dos meus próprios estudos, os de Bonilla (2005) e Gordon (2006). Gordon fala, no caso, de uma "sociologia operada pela mitologia". Mas o que seria, exata ou aproximadamente, uma "sociologia operada pela mitologia"?

Ora, uma sociologia operada pela mitologia parece em princípio o oposto do que se entende por sociologia. O papel reservado à mitologia dentro das análises sociológicas tem sido, de praxe, o de confirmação do real ou, ainda mais, o de falsa consciência. Lévi-Strauss, na apresentação de sua empresa de análise mitológica (Lévi-Strauss, 2010, p. 29), estabelecia a diferença entre o mundo social, submetido a certas constrições fatuais, e o mundo da mitologia, em que qualquer coisa pode acontecer. Que sociologia seria possível num campo em que tudo pode acontecer?

Pode-se voltar ao início deste artigo, onde se fazia uma breve história do fracasso da etnologia em lidar com os etnônimos, esse ruído inarticulado. É fácil comprovar que todas as tentativas de interpretação têm se dirigido a atribuir uma extensão aos etnônimos, a identificá -los como linhagens, subgrupos, unidades locais atuais ou pretéritas. Caberia assumir esse fracasso reconhecendo que o modo em que os etnônimos se fazem notar não é extensivo, mas intensivo. O conceito (ou o binômio) está tomado aqui de Deleuze por meio de Viveiros de Castro (2007), que o aplica à sua teoria do parentesco. Um sentido sem solução de continuidade com o par extensivo-intensivo da semântica, correspondendo, respectivamente, à denotação e à conotação. Há no intensivo um excesso de significação sem aplicação definida. O termo nawa, que a glosa habitual faz equivaler a "gente", ou seja, uma extensão, revela-se assim - remete-se a um trabalho meu muito anterior, Calavia Sáez (2002) - como o ponto intensivo por excelência do vocabulário pano. Sem deixar de atuar como um formador de gentilícios, nawa cunha os coletivos de humanos, animais ou espíritos, designa um inimigo genérico, designa o branco. Longe de ser um simples pluralizador, um sufixo como nawa acumula sentidos contraditórios e organiza ao seu redor toda a cosmologia. Mais do que um formador 
de gentilícios, nawa é um formador de sujeitos: acoplado a qualquer término - nomes de animais são os mais comuns, mas nada impede que entrem na lista seres inanimados - ele anuncia a aparição de um novo agente no discurso ${ }^{7}$. Como foi dito no início, há muito tempo se tornou óbvio que nada pode se esperar dos etnônimos que interesse a uma sociologia extensiva, ou, dizendo de outro modo, a uma sociologia que descreva sociedades. Mas uma sociologia que se limitasse à extensão e à descrição da "sociedade" assim definida estaria fadada a ser apenas um lado da sociologia.

Embora indiscutivelmente "nomes", os etnônimos apontam para um valor da nominação que está nas antípodas daquele apresentado no relato bíblico, no Gênese, quando Yaveh apresenta ao Homem todos os seres criados para que lhes outorgue um nome. Lá, a nominação do criado contrasta com a existência de um deus criador que se dá a conhecer (mais tarde, no Êxodo) por uma expressão pronominal, "é quem é". Negando-se a ser nominado, o deus pretende eludir toda determinação, ou pretende acumulá-las todas. Nessa pragmática bíblica do nome, nominar equivale a domesticar e dominar, daí também a diminuir: o inominável é, em proporção inversa, poderoso.

No caso que se ocupa aqui, dá-se o contrário: o nome é uma potência que escapa às determinações, e acontece assim pela sua proliferação, pela sua irredutibilidade à extensão.

Os etnônimos pano têm um valor que inverte o de outros sistemas nominais que coexistem no mesmo espaço cultural, por exemplo, o do sistema de nomes pessoais transmitidos segundo um cálculo Kariera (Melatti, 1977; Kensinger, 1991). Esses xutabu, identificando indivíduos de gerações alternas, estabelecem grupos de nominação com funções sociais claras, classificam produtivamente - o que implica que o conjunto de nomes é limitado em comparação com o conjunto de nominados: a nominação é econômica. O nome insere o seu portador, com estrema eficiência, num mapa social prévio. Bem outro é o destino desses etnônimos seriais, cuja proliferação tem um paralelo com a marcada tendência ameríndia a fazer do nome um patrimônio de primeira importância (Gonçalves, 1992). Se os tupinambá do século XVI se esforçavam em ganhar nomes a custa dos inimigos 
mortos (Gonçalves, 1992, p. 52) e se entre os Kayapó um sujeito pode colecionar até 15 nomes dos quais os seus maiores devem lembrá-lo (Gonçalves, 1992, p. 61-62) não é, obviamente, para dar-lhes um uso cível, para organizar a comunicação do dia a dia, para ingressar com ele numa classificação: eles são uma riqueza. São nomes suntuários ${ }^{8}$. O nome capturado se possui, eventualmente, se exibe. As maiores listas de etnônimos pano, embora não sejam entendidas como patrimônio, também se possuem e se exibem: não estão em mãos de qualquer um, mas de indivíduos, tipicamente velhos, que acumulam saber, e que o demonstram oferecendo essa profusão esotérica em lugar do conjunto econômico de termos que os outros conhecem?.

Que os etnônimos sejam intensivos supõe-se que eles são infinitos, e não por hipérbole; eles não têm mesmo limite. Sempre é possível lembrar, desenterrar e inventar mais um. Longe do cálculo mercantil em que o valor está ligado à escassez, trata-se aqui de um valor vinculado a essa ausência de limites.

Se a sociologia é operada pela mitologia, é precisamente neste sentido: tudo pode acontecer nela quando se desliza para esse "mas na verdade somos [...]" dos etnônimos; a mitologia abre para a sociologia uma dimensão que não é a da sua representação normativa, ideal ou utópica. Ou seja, não se trata de que a mitologia ofereça um modelo a imitar ou a evitar pela história real - embora nada lhe impeça alguma vez fornecer materiais para isso - mas uma abertura em direção a todo tipo de possíveis - em geral improváveis.

\section{Associologia Ameríndia}

Essa ideia parece estranha para uma sociologia feita por especialistas - legisladores, pensadores políticos ou sociólogos. Ao defrontar-se com mundos em que essas profissões não estão institucionalizadas, uma pesquisa etnográfica costuma procurar seus equivalentes. Em geral consegue achá-los. Na minha própria pesquisa, essa procura acabou de um modo diferente. Os Yaminawa, com efeito, não prodigam o discurso sociológico, à diferença, por exemplo, dos Huni Kuin - de resto tão próximos - que têm oferecido aos seus etnógrafos ricas exegeses de seu sistema de parentesco, e todo um pensamento explí- 
cito sobre o modo em que deve se viver (Kensinger, 1995; McCallum, 2001). Minhas indagações a esse respeito sempre obtiveram resultados precários, forçados (se eu insistia em perguntar) e contraditórios. Isso, ao mesmo tempo em que os Yaminawa narravam com entusiasmo seus shedipawó, suas histórias dos antigos. Certa vez (me referi em várias ocasiões a esse mesmo episódio, especialmente em Calavia Sáez 2006; 107-113), obtive de um dos líderes do grupo essa descrição sociológica já citada, que definia os Yaminawa como um conjunto de quatro seções ordenadas segundo analogias animais. Entusiasmado com o detalhe e a elegância do sistema insisti em obter confirmações dela com outros interlocutores. Absolutamente em vão: ninguém tinha ouvido falar disso, e acabei arquivando a preciosa exegese como um fruto da criatividade, talvez excessiva, de um indivíduo particular de resto muito habituado ao diálogo com antropólogos. Apenas um tempo mais tarde, quando voltei a tratar desse assunto com um sujeito que inicialmente tinha negado reconhecer aquela descrição, veio uma resposta na linha da mito-sociologia antes proposta: "mas sim, isso é o que contam os shedipawó, todo o mundo sabe".

Mas onde é que os shedipawo contavam isso? O tema mais recorrente da mitologia yaminawa é o das difíceis relações com os afins, sendo que essa afinidade se da comumente entre espécies. Aliás, é na mitologia onde é usado com enorme freqüência o termo que denota a afinidade potencial (bibiki, o termo para primo/a cruzado bilateral, parceiro sexual previsível) que no dia a dia é cuidadosamente evitado. Via de regra, um animal o usa no mito para se dirigir a um humano, pouco antes ou depois de adquirir forma humana ele mesmo e iniciar relações sexuais com ele. Esposas, esposos ou cunhados surgidos desses encontros mantêm, depois dele, uma relação difícil, porque uma persistência corporal que sobrevive à transformação os faz incompatíveis com os humanos: impossibilidade de subsistir muito tempo num meio físico diferente, hábitos alimentares excessivos ou repugnantes, ferocidade. Às vezes, o motor do drama é o inverso: é o desconforto com uma condição presente o que empurra a um humano ou a um grupo de humanos a se transformar em animal, seja nesses mitos de origem das queixadas seja nesse outro em que os humanos decidem virar onças porque (segundo o interessante comentário de um intérprete) 
"estavam cansados de sua cultura". Os nomes compostos com nawa são ubíquos nessas histórias, designando indistintamente coletivos ou indivíduos; mesmo se não o fossem, persistiria um mesmo princípio comum à mitologia e à etnonímia.

Os etnônimos não são a-sociológicos: eles têm um valor estruturante, mas não no sentido rígido e estável de uma sociologia que se exprima num discurso específico sobre "o social", e defina partes e todos, mas dentro de uma mitologia. Veja-se a formulação de Deleuze e Guattari no "Anti-Édipo", citada por Viveiros de Castro (2007, p. 111):

[O]recurso ao mito é indispensável, não porque ele seja uma representação transposta ou mesmo invertida das relações reais em extensão, mas porque apenas o mito determina conformemente ao pensamento e à prática indígenas as condições intensivas do sistema (o sistema de produção inclusive).

Detalhando, no caso dos etnônimos -nawa (esse juízo poderia se ampliar, provavelmente, a sistemas semelhantes) essa mitologia conduz a dois princípios: um, que o parentesco, na verdade, não se limita a uma espécie humana - a aliança por excelência é essa que acontece no mito, não como um acerto entre humanos mas como um encontro sempre conflitivo entre espécies, e outro, que o ponto ideal do parentesco é esse, atingível apenas fora do mundo dos humanos vivos, do entre si, da negação da aliança, como foi exposto bem no início deste artigo.

Ora, como observa Viveiros de Castro (2007, p. 113), aludindo a duas famosas passagens de Lévi-Strauss: “[...] a nostalgia de uma comunicação originária entre todas as espécies não é exatamente a mesma coisa que aquela nostalgia da vida "entre si" responsável pela fantasia do incesto póstumo. Muito ao contrário. Ou não?".

As duas "nostalgias" vêm se encontrar no espaço que fica além desse "[...] mas na verdade nós somos [...]". Esse refrão é o aviso de que está se transpondo o limiar entre uma sociologia extensiva, acessível aos censos, onde dar nomes equivale a identificar filiações, para uma outra intensiva, que não é suscetível desse tipo de descrição porque inclui todas as contradições possíveis, mas que é oferecida pelos nativos como "mais verdadeira". 
Essa hierarquia poderia ser diferente, poderia ser exatamente a oposta: "sou isto e tudo o contrário, mas de fato sou o que diz o meu documento de identidade". É essa, em último termo, a fórmula pregada pela legalidade do estado. Mas no caso que nos ocupa o mais verdadeiro é aquilo que não pode ser objeto de comprovação demográfica. Na análise isso não equivale, quiçá seja necessário dizer, a uma opção preferencial pela ficção inconseqüente, a um desprezo pelos dados empíricos da vida social, preteridos em favor de noções nebulosas. Porque os efeitos dessa "mitologia" são, no mínimo, tão tangíveis quanto os da legislação social regular ${ }^{10}$. Tão tangíveis, mutatis mutandis, quanto os que a mitologia do Édipo tem sobre a ordem aparente da família burguesa. Em outras palavras: a mitologia não tem, neste caso, muita utilidade, se alguma tem, para guiar o correto funcionamento das relações sociais; mas ela atua, sim, e de forma poderosa e constante, alterando essa ordem explícita, tirando-a com frequência dos eixos e forçando uma e outra vez a sua reinvenção, reafirmação ou reelaboração. Mas isso é também sociologia, ou deveria ser.

A mitologia, é claro, não se limita a causar perturbações na vida cotidiana: nada impede que o intensivo faça empréstimos à extensão. Ou seja, a vida é constantemente submetida a reformas, que podem ser explicadas ou legitimadas por uma alusão a esse outro domínio; já fiz antes um resumo das diversas descrições que, usando os etnônimos como termos, se esboçam desde diversas perspectivas sobre a sociologia yaminawa. Essas perspectivas não são visões diferentes de um mesmo modelo lógico, mas propostas em conflito feitas por indivíduos não sujeitos a um consenso: mulheres, chefes, anciãos... Nenhuma dessas perspectivas são garantidas por uma prática que as transcenda, a não ser essa prática da instabilidade que garante todas e nenhuma. Os etnônimos são instrumentos perfeitos do dissenso: eles se esquecem com a mesma facilidade que se rememoram, podem ser invocados por tais ou quais sujeitos sem necessário referendo de outros, suas concreções são descartáveis, transitórias. Como diz Guerreiro, neste mesmo volume, para o caso Kalapalo, "A circulação de pessoas e coisas, elicitada nos rituais regionais, precipita a emergência de donos em escalas diversas, que 'cortam' essa rede heterogênea e decantam 
partículas de identidade. O que os etnônimos indicam não são 'grupos', mas sim posições em uma história geograficamente situada".

Dar destaque a uma dimensão intensiva como a dos etnônimos, respeitando o desígnio dos nativos que aludem a ela, significa trazer para a nossa análise um aspecto muito concreto de sua sociologia, o balanço entre as formas extensas, legisladas, comprováveis, e esse outro fundo intensivo do qual pode surgir a cada momento uma ruptura dessas formas extensas, uma transformação que não conta com modelos, mas sim com poderosos motivos.

\section{O Um ao Lado}

Há uma correlação imediata entre a visibilidade (ou invisibilidade) dessa malha etnonímica intensiva e o rendimento (ou não rendimento) da descrição extensiva da morfologia social; creio perceber essa correlação no conjunto do sudoeste amazônico e, provavelmente, muito além dele. Em outras palavras, ou se dá realce à vertente intensiva da socialidade ou se afirmam modelos e códigos: cada um desses aspectos vive à revelia do outro. Não é casual que Keifenheim (1992) reservassem o qualificativo de "eclatés" aos grupos que tinham pouco que dizer a respeito de sua morfologia social, flutuavam entre modelos pobres ou fragmentados e para compensar - ou para piorar - tinham apenas nutridas listas de supostos subgrupos. Tampouco que no Xingú - como menciona Guerreiro, neste volume - a equação um povo = uma aldeia, imposta pelo regime indigenista, tenha ocultado por muito tempo esse tipo de proliferação de identidades, que podem voltar a ser visíveis quando, por qualquer motivo, esse regime se afrouxar. Na hora de estabelecer uma ordem extensiva, de definir unidades, totalidades, um regime imposto desde uma agência indigenista pode ser tão efetivo quanto o pleno vigor de modelos tradicionais. A legitimação de um modelo, o seu cultivo pela autoridade tende a represar a manifestação dessa outra dimensão intensiva que, obviamente, se deixará ver muito mais se essa autoridade não chegar a se consolidar, ou entrar em crise. Seria um erro entender que esse balanço entre realização e potencialidade deva ser o mesmo em toda a parte, ou que possa ser reduzido a efeito de uma maior ou menor vulnerabilidade a fatores coloniais. 
Aquilo que se chamava páginas atrás "grade oficial", ou seja, o conjunto de etnônimos que se encontrará em qualquer meio impresso, sejam documentos da FUNAI, das ONGs ou do próprio Movimento Indígena, nos mapas, na literatura etnográfica, nas notícias de jornal, é o resultado de um processo colonial, análogo ao descrito por Wagner (1974) que se esforçou em coagular uma série de "sociedades indígenas" em paralelo com um conjunto de nomes de variadas procedências. Não se deve banalizar o processo: ele foi longo, continua em aberto, contou e conta com contribuições muito variadas, da parte indígena e da parte dos "brancos", e obteve resultados mais plenos em uns lugares do que em outros. Mas seu principal resultado foi definir um conjunto de grupos, sociedades, povos ou até de nações indígenas. O processo de etnogênese não é, como um sobrevoo pelas palavraschave da literatura poderia fazer pensar, o apanágio de povos com escassa visibilidade ou distintividade: ele se produziu em toda e qualquer parte onde uma etnia discreta e bem delimitada possa ser doravante identificada. Sua consistência tende a crescer até ficar similar à dos modelos europeus: de fato, não faltam agora carteirinhas que identificam a pertença a povos concretos, e essas assembleias que pontuam o cotidiano da política indígena perfazem uma figura hiper-realista das sociedades nativas, com o concurso de virtualmente todos os seus membros - um feito que nunca estará ao alcance dessas sociedades maiores que forneceram o modelo. Os especialistas costumam tomar ao pé da letra essas unidades, esses grupos ou sociedades cujo perfil foi elaborado pela demanda de uma política colonial que precisava de uma grade definida de partes e de todos, e de uma estrutura política proporcional ${ }^{11}$, e também em prol de uma tradição sociológica que demandava grupos como unidade de estudo. Daí a atribuir, por exemplo, sistemas de parentesco, histórias ou cosmologias discretas a essas unidades há apenas um passo que se dá constantemente. Daí a atribuir a essas "unidades" uma história unificada, uma cosmologia ou uma mitologia discretas, um patrimônio comum e diferenciado -em soma, a levar essa "unidade" a sério sem restrições - não há mais que um passo, e esse passo é dado com frequência. Mas é bom lembrar, seguindo a análise de Wagner, que o que serviu como esquadra e prumo 
a toda essa construção foi um conjunto de nomes, apenas nomes. Na sua procura por grupos reais, a etnologia e o indigenismo fizeram algo mais do que pretendiam: eles criaram grupos, segundo esses nomes. A correspondência entre esses grupos e unidades similares anteriores a esse processo fica sempre aberta a debate.

O processo não foi, no entanto, um simples equívoco: ele teve efeitos muito reais. Ou seja, os grupos que tal processo criou atuam, de fato, como grupos, que, entre outras coisas, foram criados porque o processo contou com a contribuição de agentes políticos indígenas que embarcaram numa indigenização da sociologia dos brancos. É obvia a alusão a Sahlins (1997) e partindo dele a de Carneiro da Cunha (2009). Enquanto no mundo dos Estados-Nação o conceito de sociedade está sendo cotado para baixo, e termos como fluxos, redes e associações parecem mais significativos que ele ${ }^{12}$, entre os povos sem estado (ou sem estado próprio), a "sociedade" dá provas de boa saúde. Ele é fundamental, por exemplo, na arena política, onde sair dizendo que as supostas "sociedades indígenas" são apenas nomes, ou modos de organizar diferenças, seria muito mal recebido. Os direitos territoriais e as vantagens éticas que eventualmente se atribuem ao mundo indígena são atributos de "sociedades". Em nenhum outro lugar a imaginação ocidental encontra um exemplo melhor acabado de todo o que de mais positivo o conceito de sociedade podia sugerir: consenso, identidade, reciprocidade, comunidade. Há um padrão comum a toda uma série de "aspeamentos" dos conceitos fundamentais das ciências sociais: "cultura", "sociedade", talvez "religião" e um provável etc. Depois de terem sido construídos com ajuda desse espelho fornecido pelo outro, eles são descartados parcialmente, ou seja, descartados como universais mas reinstaurados como condições da personalidade jurídica do outro.

Uma última cláusula adversativa: apesar dessa realidade que seria inepto negar às "sociedades" indígenas e à grade etnonímica que as organiza, não se pode cair no erro de exagerá-la. Ou seja, existem as sociedades indígenas porque elas foram criadas num processo do qual temos farta informação. Mas não são elas as únicas que aí existem. As sociedades indígenas existem, sim, mas "ao lado", com esse tipo de lateralidade que Deleuze atribui ao Um e ao Todo com respeito às 
multiplicidades. Esses etnônimos, dos quais se ocupa neste artigo, que durante muito tempo foram vistos como ruído sem valor para uma definição das sociedades indígenas, têm, sim, o valor muito considerável de nos situar de volta nesse outro lado em que os grupos continuam sendo, agora mesmo, apenas nomes, e nada menos do que nomes.

\section{Notas}

1 Este artigo utiliza partes de um pré-print (Calavia Sáez, 2014), elaborado como ponto de partida do seminário "Nomes, pronomes e categorias", e retoma argumentos já presentes em trabalhos anteriores (Calavia Sáez, 2002; 2006).

2 O foco desta descrição está nos grupos de língua Pano do sudoeste amazônico, incluindo porém referências aos seus vizinhos de etnias e línguas muito diversas: suspeita-se que boa parte das análises deste trabalho poderia se aplicar a eles e, talvez, a outros povos da Amazônia e das Terras Baixas sul-americanas. O trabalho não se furtará, de resto, a reflexões tão amplas quanto se quiser sobre a relação entre nome e grupo social.

3 Veja-se a discussão entre Riviére e Fajardo a respeito da relevância desses subgrupos, parte de um debate entre Rivière e um grupo de especialistas nas Guianas que revisou a sua obra (Rivière et alii, 2007, p. 261 e 266).

4 Esse etnocentrismo já tinha sido comentado previamente, por Lévi-Strauss entre outros: ver Viveiros de Castro (1996, p. 123 e ss.) sobre a alternância entre essa restrição da condição humana aos limites da aldeia e a sua ampliação para peixes, porcos selvagens ou pássaros são também "gente que nem nós". Essa alternância, veja-se, corresponde à polaridade entre a autodesignação e o conjunto de etnônimos, que com frequência são zoônimos.

5 Os quais, de outro lado, não raro coincidem, como quando os índios absolutamente selvagens são identificados como "índios brancos".

6 Termos como Shuar (Taylor, 1986) ou Matis (Erikson, 2004) são bons expoentes da homologia entre as auto e as heterodesignações. Ambos os artigos citados são, aliás, excelentes exposições dessa elasticidade aqui descrita de um modo sumário.

7 Guerreiro e Deturche, neste volume, indicam um significado de "dono" para termos análogos a "nawa". O discurso sobre os "donos" não fez uma aparição significativa na minha pesquisa, em que queixadas ou árvores que eram "gente" o eram todos e cada um, e não por intermediação de um "dono". Mas há pelo menos um caso, o de Yuwasinawa, o sovina, dono das plantas cultivadas e especialmente da macaxera (Yuwa), em que "nawa" aparece com esse valor. Curiosamente, dawa -um termo idêntico, considerando a pronúncia efetiva de alguns Pano, incluídos os próprios Yaminawa - significa "dono", assim como "povo" ou "gente" entre os Zuruahá (Gordon, 2006, p. 62).

8 Sobre os nomes Kayapó como riqueza, veja-se todo o capítulo II de Lea (2012).

9 Não que os próprios nomes xutabu, uma vez perdida a sua função social por puro esquecimento dos jovens, que usam no cotidiano os nomes em português, não possam se tornar também um item suntuário semelhante. No meu trabalho de campo, os "nomes indígenas" ou "nomes verdadeiros" deviam ser sempre requisitados de pessoas mais velhas, que ainda possuíam a sua memória. 
${ }^{10}$ Legislação regular cujo caráter não menos ficcional costuma-se eludir nas nossas descrições: normas de casamento, regras da chefia ou critérios de filiação que na prática não se cumprem, que são remetidas aos bons costumes dos tempos dos antigos corroídas pelo contato. Há certo sofisma em que a norma seja sempre remetida ao conhecimento efetivo, e o seu fracasso aos imponderáveis. Talvez, vale a pena deixar claro que o par extensivo-intensivo em modo algum coincide com um par factual-ficcional.

11 Algo parecido foi feito com a grade de classificação linguística, que por sua parte deu também uma contribuição importante a essa grade geral. É fácil se esquecer de que ao usar taxons tomados da etnolinguística estamos apenas usando mais uma classificação externa, de utilidade indubitável, mas não dotada de outro tipo de realidade transcendente.

12 Veja-se o debate organizado por Ingold (1996), que logo completará os 20 anos, mas ainda pode servir de referência à crítica do conceito de "sociedade" - e sua eventual substituição por "socialidade".

\section{Referências}

ALVES DA SILVA, Alcionílio Bruzzi. A civilização indígena do Vaupés. Roma: Libreria Ateneo Salesiano, 1977.

BONILLA, Oiara. O bom patrão e o inimigo voraz: predação e comércio na cosmologia paumari. Mana: Estudos de Antropologia Social, Rio de Janeiro, v. 11, n. 1, p. 41-66, 2005.

CALAVIA SÁEZ, Oscar. Nawa, Inawa. Revista Ilha, PPGAS-UFSC, Florianópolis, v. 4 n. 1, p. 35-57, 2002.

CALAVIA SÁEZ, Oscar. O nome e o tempo dos Yaminawa: Etnologia e história dos Yaminawa do Rio Acre. São Paulo: Editora da UNESP, 2006.

CALAVIA SÁEZ, Oscar. Nomes, pronomes e categorias. Antropologia em Primeira Mão, PPGAS-UFSC, Florianópolis, v. 138, p. 5-17, 2014.

CARNEIRO DA CUNHA, Manuela. Pontos de vista sobre a floresta amazônica: xamanismo e tradução. Mana: Estudos de Antropologia Social, Rio de Janeiro, v. 4, n. 1, p. 7-22, 1998.

CARNEIRO DA CUNHA, Manuela. Cultura e cultura: conhecimentos tradicionais e direitos inteletuais. In: Paulo: Cosac \& Naify, 2009. p. 311-373. . Cultura com aspas. São

DESHAYES Patrick; KEIFENHEIM, Barbara. La conception de l'autre chez les Kashinawa. Université Paris VII DETIENNE, M. L'Invention de la Mythologie. Paris: Gallimard, 1982.

ERIKSON, Philippe. Qu'est-ce qu'un ethnonyme? L'exemple Matis (Amazonas, Brésil). Cahiers Amérique Latine Histoire et Memoire, [S.l.], n. 10, p. 127-136, 2004. 
FAJARDO GRUPIONI, Denise. Comparando taxonomias sociais ameríndias, investigando noções de "gente". In: COFFACI DE LIMA, Edilene; Lorena CÓRDOBA. Os Outros dos Outros: relações de alteridade na etnologia Sul-Americana. Curitiba: Editora da UFPR, 2011. p. 119-134.

GONÇALVES, Marco Antônio. Os nomes próprios nas sociedades indígenas das Terras Baixas da América do Sul BIB. Rio de Janeiro, n. 33, $1^{\circ}$ Semestre de 1992. p. 51-72.

GORDON, Flávio. Os Kulina do Sudoeste amazônico: história e socialidade. 2006. 139 p. Dissertação (Mestrado) - Museu Nacional, Rio de Janeiro, 2006.

GOW Peter. The social organization of the Native Communities of the Bajo Urubamba River. 1987. Ph.D. (These) - London School of Economics, Londres, 1987.

GOW, Peter. Gringos and Wild Indians. Images of History in Western Amazonian Cultures. In: L'HOMME AVRIL-DÉCEMBRE, 1993. XXXIIIe Année, [S.l.], n. 126-128, 1993. p. 327-348.

INGOLD, Tim et alii. Debate: The concept of society is theoretically obsolete. 1989. In: INGOLD, T. (Ed.). Key Debates in Anthropology. London: Routledge, 1996. p. 57-98.

KEIFENHEIM, Barbara. Identité et alterité chez les Indiens Pano. [S.l.]: JSA LXXVIII-II, 1992. p. p. 79-93.

KENSINGER, Kenneth M. How real people ought to live. The Cashinahua of Eastern Peru: Waveland Press, 1995.

KENSINGER, Kenneth. Panoan Kinship Terminology and Social Organization: Dravidian or Kariera, or Something Else? In: SYMPOSIUM: CLASSIC PANOAN TOPICS IN LIGHT OF RECENT RESEARCH, 1991. 47th International Congress of Americanists, New Orleans, 1991.

LEA, Vanessa R. Riquezas Intangíveis de pessoas partíveis. São Paulo: Edusp, 2012.

LEVI-STRAUSS, Claude. [1964]. O cru e o cozido: mitológicas I. São Paulo: Cosac \& Naify, 2010.

LIMA, Tânia Stoltze. O dois e seu múltiplo: reflexões sobre o perspectivismo em uma cosmologia Tupi. Mana: Estudos de Antropologia Social, Rio de Janeiro, v. 2, n. 2, p. 21-48, 1996.

McCALLUM, Cecília. Gender and Sociality in Amazonia: How Real People are Made. Oxford: Berg, 2001. 
MELATTI, Julio Cézar. Estrutura social Marubo: um sistema australiano na Amazônia. [S.l.]: Anuário Antropológico, 1977.

RIVIÉRE Peter et alii. A propósito de Redes de Relações nas Guianas.

Mana: Estudos de Antropologia Social, Rio de Janeiro, v. 13, n. 1, p. 251-273, 2007.

RIVIERE, Peter. Individual and Society in Guiana: a comparative study of Amerindian social organization. Cambridge: Cambridge University Press, 1984.

SAHLINS, Marshall. O "pessimismo sentimental" e a experiência etnográfica: por que a cultura não é um “objeto" em via de extinção (Parte II). Mana: Estudos de Antropologia Social, Rio de Janeiro, v. 3, n. 2, p. 103-150, 1997.

SEEGER, Anthony; DA MATTA, Roberto; VIVEIROS DE CASTRO, Eduardo B. A construção da pessoa nas sociedades indígenas brasileiras. Boletim do Museu Nacional, Série Antropologia, n. 32, p. 2-19, 1979.

STEWARD, Julian H. (Ed.). Handbook of South American Indians. Washington, Smithsonian Institution, 1948. v. 3.

TAYLOR, Anne-Christine. A invenção do Jivaro: Notas etnográficas sobre um fantasma ocidental. Antropologia Ecuatoriana, homenagem a Udo Oberem, Quito: Ed. Abya-Yala, 1986.

TOWNSLEY, Graham. Ideas of order and patterns of change in Yaminahua society. 1988. PhD (Thesis) - University of Cambridge, Cambridge, 1988.

VILAÇA, Aparecida. Os subgrupos Wari na história. Paper apresentado no Encontro ANPOCS GT 24, 2004. (Transformações Indígenas)

VIVEIROS DE CASTRO, Eduardo. Alguns aspectos da Afinidade no Dravidianato Amazônico. In: VIVEIROS DE CASTRO, Eduardo; CUNHA, Manuela Carneiro da. Amazônia: Etnologia e História Indígena. São Paulo: NHII/USP/FAPESP, 1993.

VIVEIROS DE CASTRO, Eduardo. Ambos os três: sobre algumas distinções tipológicas e seu significado estrutural na teoria do parentesco. [S.l.]: Anuário Antropológico 1995, p. 9-91.

VIVEIROS DE CASTRO, Eduardo. Filiação intensiva e aliança demoníaca. Novos Estudos - CEBRAP, São Paulo, n. 77, p. 91-126, 2007.

VIVEIROS DE CASTRO, Eduardo. Os pronomes cosmológicos e o perspectivismo ameríndio. Mana: Estudos de Antropologia Social, Rio de Janeiro, v. 2, n. 2, p. 115-144, 1996. 
WAGNER, Roy. Are There Social Groups in the New Guinea Highlands? In: LEAF, Murray. Frontiers of Anthropology. Nova York: D. Van Nostrand Company, 1974. p. 95-122

ZARZAR, Alonso. Radiografia de un contacto: los Nahua y la sociedad nacional. Amazonía Peruana, Lima: CAAAP, n. 14, 1987.

Recebido em 18/10/2015

Aceito em 1\%/04/2016 